\title{
Influence of Defocus Position on Laser Cutting Process in Sheet Steel
}

\author{
Lyubomir Lazov, Hristina Deneva, Erika Teirumnieka \\ Rezekne Academy of Technologies, Faculty of Engineering \\ Address: Atbrivosanas aleja 115, Rezekne, LV-4601, Latvia
}

\begin{abstract}
Some researches about influence of defocus position to carry out laser cutting technological process through melting when producing lamellae for electric motors are presented here. Experimental series at defocus position $\Delta f$ in the range - 3, $5 \mathrm{~mm}$ to $+3,5 \mathrm{~mm}$ with two grade electrical steels M250-35A and M530-50A are described, too. The experiments are performed with a technological laser system TruLaser 1030. Functional dependencies of cutting width from defocus position $b=b(\Delta f)$ have been shown. Theoretical relationships connected to the change of impact on a unit of area working spot over power density $q_{s}$ of the laser radiation and interaction time $t_{\text {proz }}$ (respectively cutting speed v), are examined too
\end{abstract}

Keywords: laser cutting, sheet steel, laser focusing.

\section{INTRODUCTION}

Production forecasts of electric vehicles show that over the next $10-15$ years it will dominate over that of petrol and diesel cars [1]. Therefore for contemporary design new challenges are appeared to development and testing on new constructions of this type of cars. They impose demand for a new innovative technology when producing lamellae for stator and rotor packages of electric motors. Given the present punching technology for each new engine model it is necessary to make a special tool for production of new design lamella. This from technological and economic character is unprofitable. In general, the production of punching tool is connected with high costs and long time for its elaboration which are justified only in serial production. An innovative technological solution for cutting of lamellae by Si-sheet metal for the stator and rotor packages provides the laser technology for contour cutting.

For adopting of specific laser technology with given technological system for cutting of lamellae to production electric motors it is necessary to make thorough particular pilot studies. To achieve the desired quality during technological process it is important to test a number of parameters (figure 1) that are directly related to technology of the laser cutting such as: cutting speed $v$; power density $q_{s}$ of laser radiation in the treatment area; repetition rate $v$; pulse width $\tau$; defocus position $\Delta f$, etc.

In this paper the influence of defocus position as factor that is very important in processing of large size $(3000 \mathrm{~mm}$ x $1500 \mathrm{~mm}$ ) steel sheets will be examined. When processing such areas it is crucial to keep the optimum operating mode throughout the treatment zone

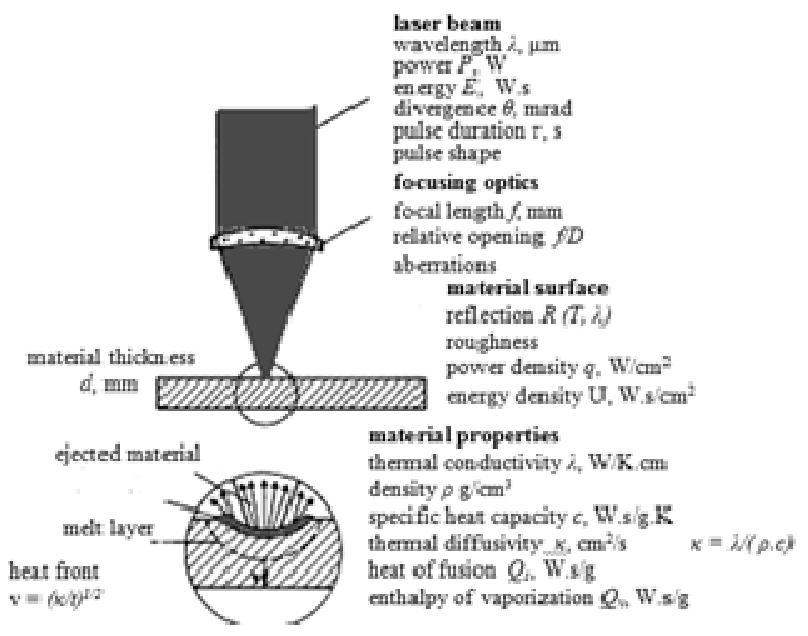

Fig. 1. Parameters which influence in the process of laser cutting [6]

The defocus position realized by the optical system provides the optimal diameter of spot $d$ which in its turn is connected with two important technological parameters: power density $q_{s}$ and impact time $t_{\text {proz. }}$. $[1,2,3,4,5]$.

\section{THEORETICAL ASPECTS}

In order to obtain a good quality in the process of laser cutting through melting, it is necessary the power density $q_{s}$ of laser radiation and the interaction time $t_{\text {proz }}$ to be at their optimum operating range providing the absorption of sufficiently energy with which could be melt material in the treatment zone 
(fig. 2). Both technological parameters $q_{s}$ and $t_{\text {proz }}$ are connected with each other and with the diameter of the working spot $d$. Role of the working radius spot $r$ $=d / 2$ and its relationship with average power $P$ and interaction time during the process are clearly seen from the dependence

$$
t_{\text {proz }}=\frac{\pi^{3} k^{2} r^{4}\left(T-T_{0}\right)^{2}}{4 a A^{2} P^{2}}
$$

where $k$-thermal conductivity;

$P$ - average power;

$A$ - absorption coefficient;

$a$ - thermal diffusivity;

$T$ - process temperature;

$T_{0}$ - ambient temperature.

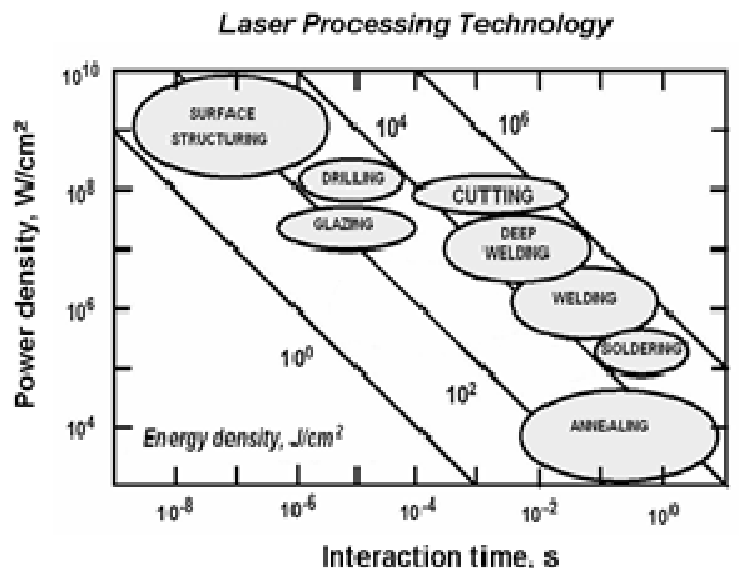

Fig. 2. Operational regimes for various processes of laser treatment

On the other hand power density in the area of working spot is given by

$$
q_{S}=P / S
$$

where $S$ is a unit of area on the working spot,

$P$ - power of the falling laser radiation on the surface.

Considering that

$$
S=\pi d^{2} / 4
$$

where $d$ is the diameter of working spot and substituting in (2) is obtained

$$
q_{S}=4 P / \pi d^{2}
$$

Diameter of the working spot $d$ is a complex magnitude and it is connected with parameters for quality of the laser radiation (figure 3 ) and with these of the optical system as you can be seen from the following dependence

$$
d=2 r=\mathrm{M}^{2},
$$

where $f$ is a focal distance,
$D$ - beam diameter,

$\lambda$ - wavelength of laser radiation,

$\mathrm{M}^{2}$ - a parameter (a number to the diffraction it describes an approximation of the actual laser beam with the Gaussian beam).

In the scientific literature $\mathrm{M}^{2}$ is also described as $K$-factor - another measure of quality. It various between $0<K<1$. In the basic Gaussian mode TEM $_{00}$ it is equal on $1 . K$ - factor is related with wavelength $\lambda$, beam divergence $\theta$ and Gaussian beam waist $r_{0}$ as you can be see from the dependence

$$
K=\frac{\lambda}{\pi \cdot r_{0} \theta}
$$

where the divergence $\theta$ is defined with a limit of the relationship (fig. 4):

$$
\theta=\lim \frac{r(z)}{z}=\frac{\lambda}{\pi r_{0}},
$$

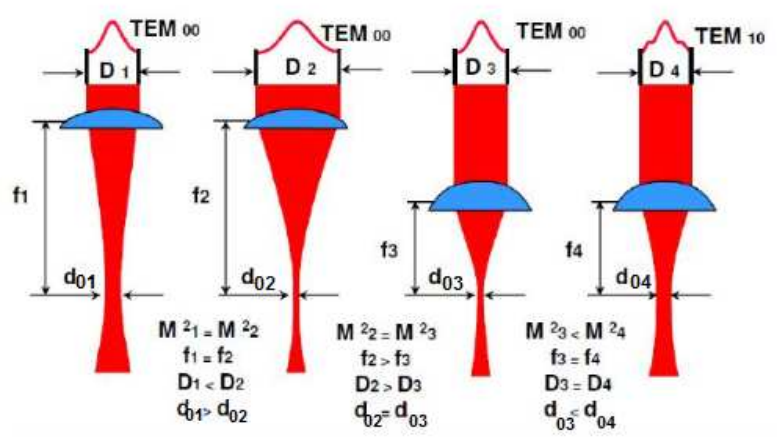

Fig. 3. Role and meaning of $\mathbf{M}^{2}, D$ and $f$ on the size of working spot $d$ [7]

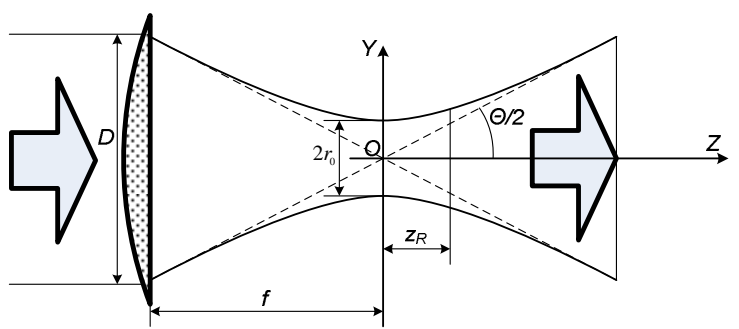

Fig. 4. A spatial distribution of the beam after its exit to the focusing system

A major parameter for the practice is the Rayleigh length $z_{R}$. It is defined as a distance from the beam waist (fig. 4) for which the cross sectional area of the laser beam is increased twice

$$
z_{R}=\frac{\pi r_{0}^{2}}{\lambda} K=\frac{r_{0}}{\theta}
$$

To realize desired qualitative technological result unto laser cutting, diameter of the working spot or its position to the working surface often is required to 
change by the optical system. Laser beam can be placed with three positions: inside the sample (fig. $5 a$ ), on the target surface (fig. 5b) and above the sample surface (fig. 5c). In cases (a) and (c) is operated at defocus position $\Delta f$. When the focus is above the sample surface, $\Delta f$ has positive values, and when it is under the surface - negative values.

When defocus position $\Delta f$ is above or under the surface, the power density $q_{s}$ reduces very quickly in comparison the operating mode - $\Delta f=0$. When $\Delta f$ is larger than Rayleigh length (fig. 4), the diameter $d$ of the working spot is given by equation

$$
d=\frac{D\left(z^{\prime}+\Delta f\right)}{f+z^{\prime}},
$$

where $D$ is the diameter of laser beam that incident on the lens, $f$ - focal distance of the lens, and the parameter $z^{\prime}$ is defined by expression

$$
z^{\prime}=\frac{d_{f} f}{D-d_{f}},
$$

where $d f$ is diameter of working spot in focus.

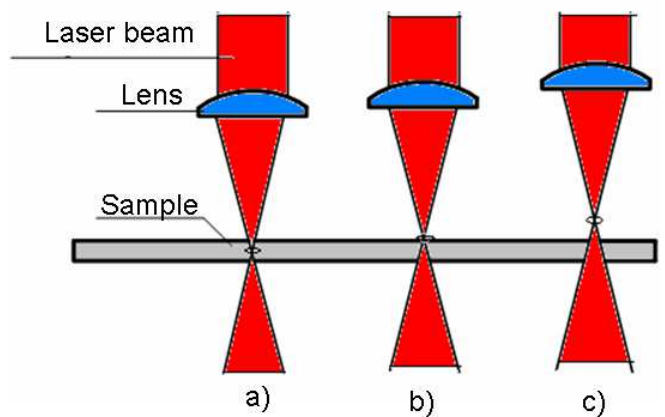

Fig. 5. Location of the working spot to the sample surface: a). inside the sample $(\Delta f<0)$; b). on the surface $(\Delta f=0)$; c). above the surface $(\Delta f>0)$

When condition $\Delta f<z_{R}$ is satisfied, the diameter of working spot almost does not change and therefore the power density of laser radiation reduces very small at compared to that in $\Delta f=0$.

By the equation (8) we can see that if $\Delta f>z_{R}$ the increasing of defocus position $\Delta f$ the diameter $d$ of working spot is increased too, as the dependence is linear. The power density $q_{s}$ is inversely proportional to the second degree of diameter $d$ (3). It follows that the power density decreases very quickly with increasing of defocus position $\Delta f$, as well as optimal technological cutting regime is interrupted and required quality of cut is impossible to obtain.

\section{RESULTS}

To study the influence of defocus position $\Delta f$ on kerf width $b$ and quality, some experiments were carried out in conditions close to industrial system TruLaser 1030 [8]. Samples of electrical steel M250-35A and M530-50A suitable for lamellae of rotor and stator packages with thickness respectively $0,35 \mathrm{~mm}$ and $0,50 \mathrm{~mm}$, are used. As a laser source in the system is Disk Yb:YAG laser emitting a radiation with wavelength $\lambda=1,03 \mu \mathrm{m}$.

On based our studies and methodic published in previous papers $[9,10,11]$, to current report, the parameters systemized in table 1 are selected as constants. The study influence of defocus position $\Delta f$ is realized in the range from $-3,5 \mathrm{~mm}$ to $+3,5 \mathrm{~mm}$ i.e. as well as with immersed focus and with taking out above the surface (see fig. 5).

There are studies on the effect of defocus position to the width input and output of the cut i.e. dependencies $b_{\text {in }}=b_{\text {in }}(\Delta f)$ and $b_{\text {out }}=b_{\text {out }}(\Delta f)$, are studied too. Concerning the quality of treatment zones and areas around them were carried out optical observations with microscope Neophot2 CARLZEISS JENA [12] at a magnification of 10 to 2 000 times.

Table 1

Technological input parameters for laser system trulaser 1030

\begin{tabular}{|l|l|}
\hline Parameter & Value \\
\hline power $P, \mathrm{~W}$ & 2000 \\
\hline cutting speed $v, \mathrm{~m} / \mathrm{min}$ & 50 \\
\hline repetition rate $v, \mathrm{~Hz}$ & 20000 \\
\hline nozzle diameter $\emptyset, \mathrm{mm}$ & 1,7 \\
\hline pressure of $\mathrm{N}_{2} p, \mathrm{bar}$ & 14 \\
\hline focus distance $f, \mathrm{~mm}$ & 200 \\
\hline
\end{tabular}

Obtained results for functional dependencies of input width bin and output width bout to the defocus position $\Delta f$ for both grade steels are given respectively in fig. 6 and fig. 7 .

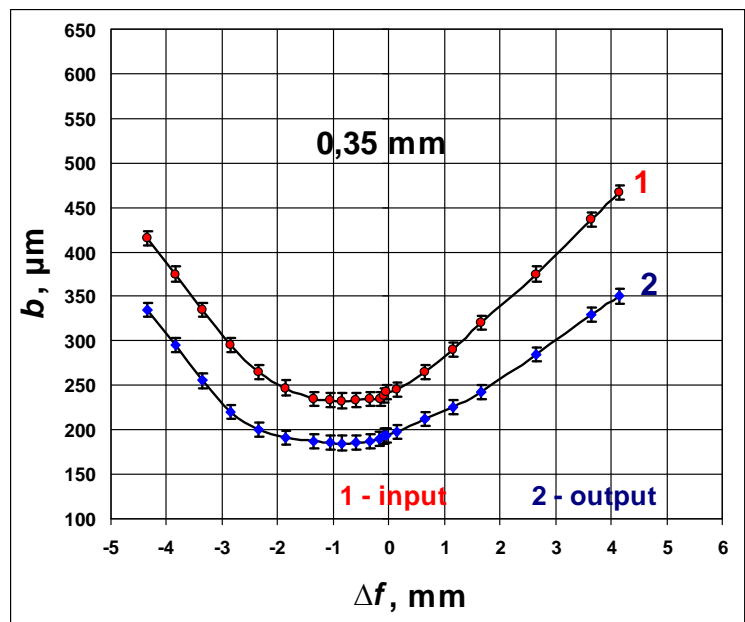

Fig. 6. Graphics of experimental dependencies $b_{i n}=b_{\text {in }}(\Delta f)$ and $b_{\text {out }}=b_{\text {out }}(\Delta f)$ for samples M25-35A 


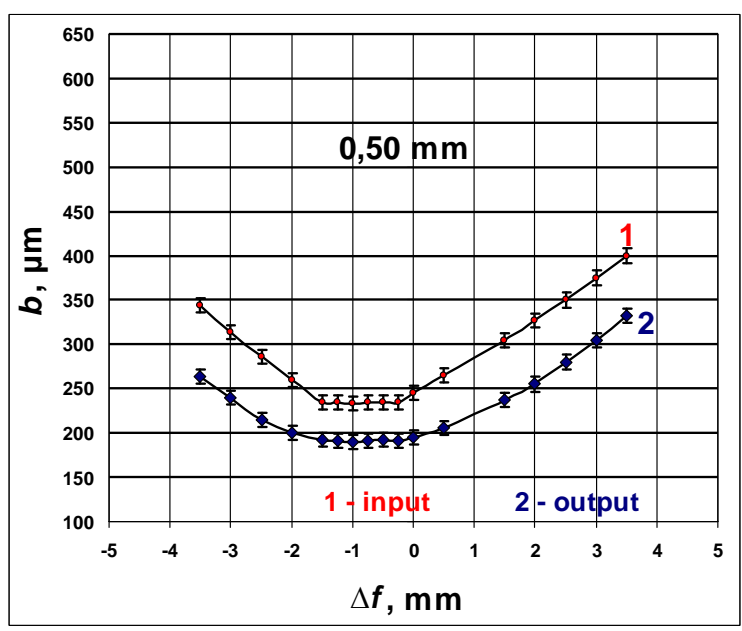

Fig. 7. Graphics of experimental dependencies $b_{\text {in }}=b_{\text {in }}(\Delta f)$ and $b_{\text {out }}=b_{\text {out }}(\Delta f)$ for samples M530-50A

Accumulated molten drops on the cutting edge are noted too on the samples with thickness $0,35 \mathrm{~mm}$ when defocus position is $\Delta f>+2,65 \mathrm{~mm}$ (fig. 8a) and $\Delta f>-3,5 \mathrm{~mm}$ (fig. $8 \mathrm{~b}$ ).
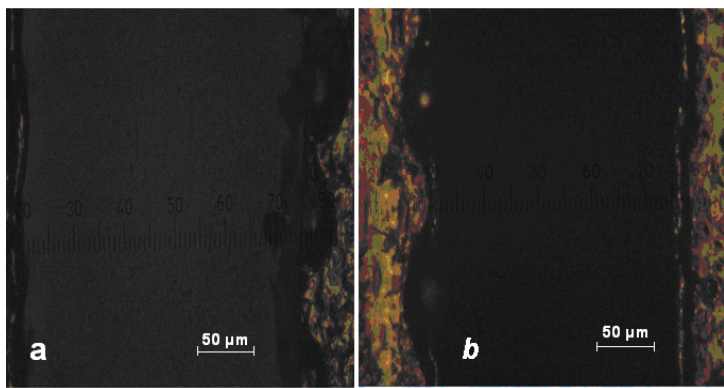

Fig. 8. Photographs of samples with tickness $0,50 \mathrm{~mm}$ and $0,35 \mathrm{~mm}$ at defocus margin $\Delta f$ greater than $+2,5 \mathrm{~mm}$ and $-3,5 \mathrm{~mm}$
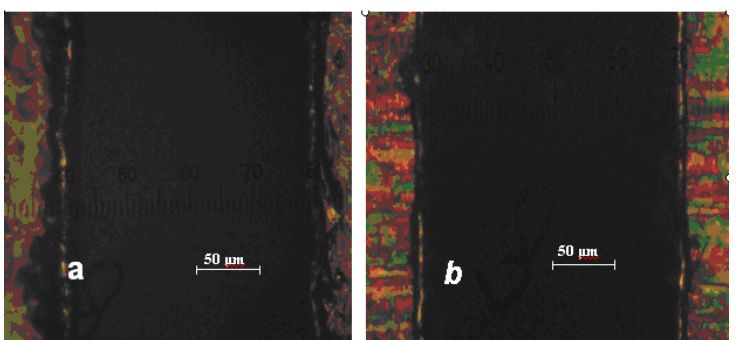

Fig. 9. Photographs of samples M250-35A at defocus position $\Delta f=-0,85 \mathrm{~mm}$ and $\Delta f=-1,0 \mathrm{~mm}$ for samples of M530-50A

Optical observations of cutting zone shown some good quality results at values of $\Delta f=-0,85 \mathrm{~mm}$ (fig. 9) и $\Delta f=+0,65 \mathrm{~mm}$.

\section{DISCUSSIONS}

From the analysis of experimental results it can be made following conclusions:

- With increasing of defocus position $\Delta f$ in a plus direction up to $+3,5 \mathrm{~mm}$ input cutting width $b_{\text {in }}$ is increased nearly linear $\Delta b \sim 170 \mu \mathrm{m}$. But in minus direction - $\Delta b \sim 110 \mu \mathrm{m}$, i.e. there is a slight change of cutting width $b$ at immersed focus in the material.
Such trend is observed and for the output cutting width bout.

- Left parts of graphics are little steep i.e. cutting width is changed faster in minus direction. This dependence is more strongly expressed for samples with less thickness: $0,35 \mathrm{~mm}$. The rate at which input cutting width increases in the interval to variation of defocus position $\Delta f=(0,65 \div 4,15) \mathrm{mm}$ for $\mathrm{M} 250-35 \mathrm{~A}$, was $\Delta b_{\text {in }} / \Delta f=48,55 \mu \mathrm{m} / \mathrm{mm}$; and $\Delta b_{\text {in }} / \Delta f=62,5 \mu \mathrm{m} / \mathrm{mm}$ in the range $\Delta f=(-4,35 \div-1,85) \mathrm{mm}$.

- Significant change of the cutting width $\Delta b$ in the range of defocus position $\Delta f=(-0,15 \div-1,35) \mathrm{mm}$ for the samples of steel M250-35A and $\Delta f=(-0,25 \div-1,5) \mathrm{mm}$ - at samples of M530-50A, is not observed. This is explained by the fact that in the indicated interval are and the values of beam waist (Rayleigh length $z_{R}$ ). Cutting width is changed by $\Delta b= \pm 5 \mu \mathrm{m}$ in the above ranges of defocus position $\Delta f$.

- Microscopic observations and analyzes are shown a good cutting quality on the input as well as on the output when defocus position were in the range $\Delta f>+1,0 \mathrm{~mm}$ and $\Delta f>2,0 \mathrm{~mm}$ for both samples. This is due to the fact that at these technological regimes obtained melt was removed well from the $\mathrm{N}_{2}$ gas supplied in the treatment zone with pressure of 14 bar.

- Minimum input cutting width $b_{\text {in }}=230 \mu \mathrm{m}$ was observed at $\Delta f=-0,15 \mathrm{~mm}$ for samples of steel M250-35A, and $\Delta f=-0,25 \mathrm{~mm}$ - for samples of M530-50A.

\section{V.CONCLUSION}

Studies have shown that the magnitudes $q_{s}$ and $t_{\text {proz }}$ influencing on the laser cutting process through melting of sheet steel material for lamellae of electric motors, are in complex dependencies with the diameter of working spot $d$ and conditions of focusing as well as with a number variables connected with the beam quality. Knowledge of the relationships between them helps to shortening the path for optimization of the technological process - it enables to evaluate the effect on each of these parameters over the studying process. Experimental and theoretical analyzes are shown that the defocus position $\Delta f$ is an important factor having an significant influence on the technological mode and on the quality of the processing. If you must use mixed units, clearly state the units for each quantity that you use in an equation.

\section{REFERENCES}

[1] Grigoryants, A. G., Osnovy lazernoy obrabotki materialov. M., Mashinostroyeniye, ISBN: 5-217-00432-0, 1989, 301s.

[2] Grigoryants A., I. Shiganov, A. Misyurov Tekhnologicheskiye protsessy lazernoy obrabotki, izd. MGTU im. N. Baumana, Moskva, ISBN 5-7038-2701-9, 2006.

[3] Schuöker, D. Dynamic Phenomena in Laser Cutting and Cut Quality. Applied Physics, 1986, B 40, pp. 9 -14.

[4] Schuöcker, D. Handbook of the EuroLaser Academy, Chapman\&Hall, London, 1998, ISBN 0412819201.

[5] Veyko, V. P. Tekhnologicheskiye lazery i lazernoye izlucheniye. Sankt-Peterburg, ITMO, 2007, 52 s. 
Environment. Technology. Resources, Rezekne, Latvia Proceedings of the $11^{\text {th }}$ International Scientific and Practical Conference. Volume III, 163-167

[6] VDI-Technologiezentrum Physikalische Technologien: „Präzise Optische Behandlung von Festkörpern Oberflächenbearbeitung" (Handbuchreihe: Laser in der Materialbearbeitung, Bd. 5) VDI-Verlag GmbH, Düsseldorf, 1996

[7] Florian Scherm Lasermaterialbearbeitung, VL_Lasermaterialbearbeitung_WS0910.pdf, powerpoint presentation- Folie 35 (35 pp); http://www.metalle.unibayreuth.de/de/download/teaching_downloads/Vorl_Fuegetec hnik/VL_Lasermaterialbearbeitung_WS0910.pdf

[8] http://www.us.trumpf.com/en/products/machinetools/products/2d-laser-cutting/laser-cuttingmachines/trulaser-1030-fiber.html

[9] Deneva, H., Izsledvane na procesa lazerno rqzane na lameli za rotorni I statorni paketi. Dissertation, TU - Gabrovo, 2014
[10] Lazov, L., H. Deneva. Investigation of Cutting Width from Laser Power and Velocity. IJETCAS, Issue 4, Vol 1, 2 \& 3, March - May, 2013, ISSN 2279-0047.

[11] Lazov, L., H. Deneva. Investigation on the Influence of the Process Parameters Power and Velocity to Laser Cutting of Lamellae. Journal of the Technical University - Sofia, Plovdiv branch, Bulgaria, Fundamental Sciences and Applications, Vol. 21, Book 2, 2015, ISSN 1310-8271.

[12] http://microscopy.zeiss.com/microscopy/en_de/products.html L. Bass, P. Clements, and R. Kazman. Software Architecture in Practice, 2nd ed. Reading, MA: Addison Wesley, 2003. [Ebook] Available: Safari e-book. 